$100 \mathrm{db} / \mathrm{cm}$. Wegen des hohen Wertes von $\Gamma_{0}$ erreicht man keine Gesamtverstärkung $\Gamma<0$.

4. Die optimale Signalverstärkung erhält man unter Bedingungen minimaler Rauschanfachung. Die Begrenzung der Signalverstärkung durch Ultraschallrauschen und Heiße-Elektronen-Effekte müßte durch Erweiterung der bisherigen theoretischen Ansätze in einer nichtlinearen Theorie noch genauer geklärt werden.

Ich danke Herrn Dr. K. J. Schmidt-Tiedemann für anregende Diskussionen, sowie den Herren D. RESToRfF und W. Funk für ihre Mitarbeit bei den Experimenten.

\title{
Studies on Semiconducting Properties of Lead Sulphide and Lead Selenide Films*
}

\author{
A. Goswami and S.S. Koli \\ National Chemical Laboratory, Poona-8, India \\ (Z. Naturforschg. 21 a, 1462-1467 [1966] ; received 14 April 1966)
}

\begin{abstract}
Some studies have been made on the semiconducting properties viz. resistivity $(\varrho)$, activation energy $(\Delta E)$, HaLL Coefficient $\left(R_{H}\right)$, mean free path $\left(l_{0}\right)$, thermoelectric power $(\alpha)$ etc. of $\mathrm{PbS}$ and $\mathrm{PbSe}$ films of thicknesses ranging from $1500 \AA$ to $35000 \AA$. The activation energies varied from 0.6 to $1.6 \mathrm{eV}$ and 0.7 to $0.9 \mathrm{eV}$ respectively for $\mathrm{PbS}$ and PbSe films depending on film thickness and temperature range. Thinner films had higher $\Delta E$ values. The thermoelectric power not only varied but also changed its sign from positive to negative with increase of temperature. Thinner films had greater $\alpha$ than corresponding thicker films. The HaLL coefficient and mobility increased particularly for $\mathrm{PbSe}$ films both with increase of film thickness and substrate temperature. The negative temperature coefficient of resistance slowly decreased and again increased passing through a minimum with rise of temperature. The semiconduction behaviour of thin films is better explained on the island structure model than by SondHeIMER's theory.
\end{abstract}

Chalcogenides of lead in bulk form have been studied in detail by many workers ${ }^{1-9}$ for their electrical, optical and other properties, since these materials have many applications in diverse fields. In the thin film-state, many investigations ${ }^{10-15}$ have been made on the photoconducting properties of these compounds, but very few results ${ }^{16,17}$ are available on the other parameters. Here we report on a detailed investigation of the semiconducting properties of $\mathrm{PbS}$ and PbSe films.

\section{Experimental}

Lead sulphide was prepared by passing $\mathrm{H}_{2} \mathrm{~S}$ gas through a solution of lead nitrate (A.R.) in distilled

* Communication No. 900 from National Chemical Laboratory, Poona-8, India.

1 M. A. Clark and R. J. Cashmass, Phys. Rev. 85, 1043 [1952].

2 E. H. Putley and J. B. Arthur, Proc Phys. Soc. London B 64, 616 [1951].

3 E. H. Putlex, Proc. Phys. Soc. London B 65, 388 [1952].

4 E. H. Putley, Proc. Phys. Soc. London B 68, 35, 38 [1955].

5 D. G. Avery, Proc. Phys. Soc. London B 64, 1087 [1951].

6 W. W. Scanlon, Phys. Rev. 92, 1523 [1953].

7 W. W. Scanlon, Phys. Rev. 109, 47 [1958].

8 R.A.Sмiтн, Semiconducting Materials, Butterworths Scientific Publications, London 1951, p. 198. water till the precipitation of $\mathrm{PbS}$ was complete. The precipitate was filtered, washed several times with $\mathrm{H}_{2} \mathrm{~S}$ water, then with warm distilled water to free from $\mathrm{H}_{2} \mathrm{~S}$ and finally with alcohol. The material was then dried in a vacuum desiccator and used for evaporation.

Lead selenide was prepared by melting the elements in atomic proportion $(1: 1)$ in vacuo in a sealed silica tube, gradually heating in a furnace to $\cong 1000^{\circ} \mathrm{C}$ (m. p. of PbSe $950^{\circ} \mathrm{C}$ ) for about six hours and cooling.

Lead sulphide and lead selenide were then evaporated from microconical silica baskets and condensed in vacuo $\left(\cong 10^{-4} \mathrm{~mm} \mathrm{Hg}\right)$ on glass substrates of suitable dimensions $(l / b=3: 1)$. The film thickness was estimated from the difference in weight before and after deposition and from the known area assuming the density of the deposited film to be that of the bulk material.

9 R. A. Smith, Physica 20, 910 [1954].

10 R. P. Chasmer, Nature 161, 281 [1948].

11 B. T. Kolomiets, Zh. Tekhn. Fiz. 18, 1456 [1948].

12 J. N. Humphrey and R. L. Petritz, Phys. Rev. 105, 1736 [1957].

13 J. N. Humphrey and W. W. Scanlon, Phys. Rev. 105, 469 [1957].

14 C. Wood, Proc. Phys. Soc. London B 69, 613 [1956].

15 F. L. Lummis and R. L. Petritz, Phys. Rev. 105, 502 [1957].

16 G. W. Mahlman, Phys. Rev. 103, 1619 [1956].

17 R. B. Schoolar and J. N. Zemel, J. Appl. Phys. 35, 1848 [1964]. 
The experimental set-up for measuring different semiconducting parameters was similar to that described before by Goswami and Jog ${ }^{18}$. All measurements were caried out in vacuo unless otherwise stated. Resistances were measured by a.c. and d.c. methods both during heating and cooling cycles with the help of a universal AVO or Tesla bridge operating on $400 \mathrm{~Hz}$ as well as on d.c. voltage. The thermoelectric power was measured both by integral and differential methods. In the former case the temperature of one end of the film was increased gradually with the help of a microheater whereas the other end was kept constant at appropriate temperature. In the latter case, the temperature at both the ends was increased, keeping a constant temperature gradient between them. General increase of temperature was facilitated by the use of an external heater. Hall coefficients were, however, measured in air in the manner described by Deokar and Goswami ${ }^{19}$.

Before starting the measurements, the deposited films were annealed well below the discontinuity temperature $\left(T_{\mathrm{d}}\right)$, the implications of which were pointed out previously by Goswami and Jog ${ }^{18}$. The mean values of several heating and cooling cycles for each specimen were taken for plotting the curves. Often a hysteresis type of loop was observed between heating and cooling which could be minimized by a better control of temperature. The maximum temperature of the measurements was always below the $T_{\mathrm{d}}$ temperature. Measurements were also repeated for different sets of films deposited more or less under the same conditions of evaporation.

\section{Results}

Before measuring the different semiconducting parameters such as resistivity, thermoelectric power, HaLL coefficient etc. for any specimen a few preliminary experiments were made to see the effects of rate of deposition, film thickness, stress and strain etc. on the resistance of the film. These were found to be similar to those already observed in the case of lead telluride films ${ }^{20}$.

\section{A. Resistivity @ and Activation Energy $\Delta E$}

PbS films: The resistivity of thin films was found to be much higher than that of the bulk material. $\log R$ vs. $1 / T$ curves were plotted for different heating and cooling cycles. In Fig. 1 it is seen that for a film of thickness $25000 \AA$ the resistance first increased with increase of temperature upto $135^{\circ} \mathrm{C}$ (region " $\mathrm{A}$ "), then decreased with the further rise

18 A. Goswami and R. H. Jog, Indian J. Pure Appl. Phys. 2, 407 [1964].

19 V. D. Deokar and A. Goswami, Intern. Symp. on Basic Problems in Thin Film Physics, Clausthal, West Germany (Sept. 1965), Abstr. p. 54. of temperature (region "B") upto the maximum temperature of our experiments $\left(\cong 350^{\circ} \mathrm{C}\right)$. During the cooling process the resistance closely followed the heating curve down to about $135{ }^{\circ} \mathrm{C}$ and continued to rise after that, but with a different slope (region "C"). During further heating cycles without breaking the vacuum path $\mathrm{BC}$ was followed almost exactly. Thus path BC exhibits the semiconducting characteristics of the $\mathrm{PbS}$ film whereas path A appears to be due to the superposition of other effects, especially adsorption of gases. The activation energies measured in the linear portions of the curve (B and $\mathrm{C}$ ) were about 1.48 and $0.6 \mathrm{eV}$ respectively for a film of thickness $25000 \AA$. Table 1 shows $\Delta E$ values for the $B$ and $C$ region corresponding to the four curves in Fig. 1. The lower activation energy

\begin{tabular}{|c|c|c|}
\hline $\begin{array}{c}\text { Thickness } \\
\AA\end{array}$ & In B region & In C region \\
\hline 3100 & $1.684 \mathrm{eV}$ & $0.650 \mathrm{eV}$ \\
7350 & 1.593 & 0.592 \\
19420 & 1.550 & 0.550 \\
25000 & 1.478 & 0.535 \\
\hline
\end{tabular}

Table 1. Variation of $\Delta E$ with thickness in different temperature regions for $\mathrm{PbS}$ films.

in the $\mathrm{C}$ region, no doubt due to the extrinsic behaviour of the films, seems to be associated with defects and faults in the film-structure, whereas the higher values of $\Delta E$ in the $\mathrm{B}$ region are due to intrinsic characteristics of the samples. It is also interesting to note that in the $\mathrm{B}$ region $\Delta E$ was increasing with decreasing film thickness. The behaviour in the A region was found to be due to the adsorption of gases by the deposited layers as shown by different curves viz. $A^{\prime}, A^{\prime \prime} \ldots$ in Fig. 1, obtained under different conditions of vacuum.

PbSe films: Lead selenide films were annealed at about $325{ }^{\circ} \mathrm{C}$ in vacuo, below the $T_{\mathrm{d}}$ temperature $\left(\cong 350{ }^{\circ} \mathrm{C}\right)$. Fig. 2 shows the variation of $\log R$ with $1 / T$ for different film thickness. During the initial heating cycles regions $\mathrm{A}$ and $\mathrm{B}$ were again observed. The cooling curves, however, did not exactly follow the previous heating path and a hysteresis type of loop was observed in the temperature

20 A. Goswami and S. S. Koli, Intern. Symp. on Basic Problems in Thin Film Physics, Clausthal, West Germany (Sept. 1965), Abstr. p. 53. 


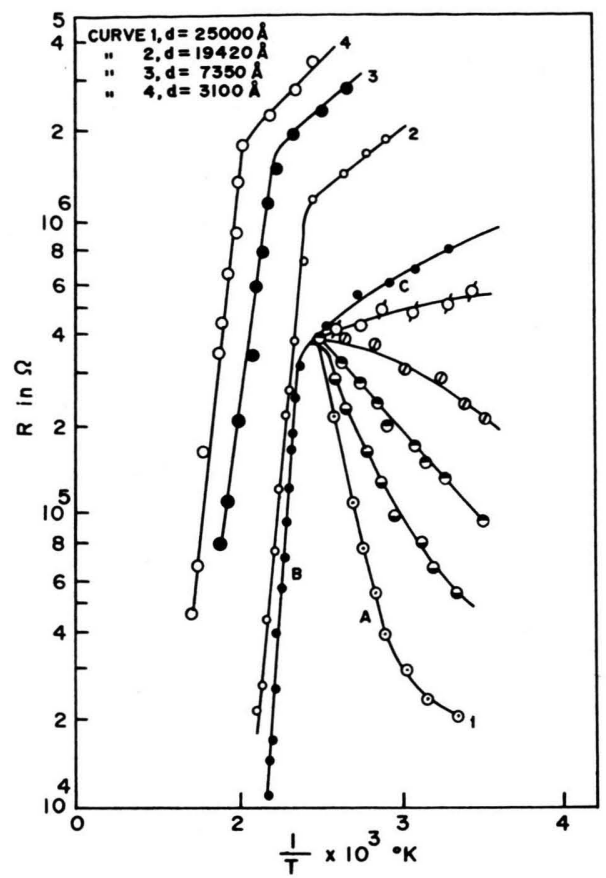

Fig. 1. Variation of $\log R$ with $1 / T$ for $\mathrm{PbS}$ films of different thickness.

range between $30^{\circ}-225^{\circ} \mathrm{C}$. At higher temperatures, however, the loop was not appreciable. It was again confirmed that the behaviour in region " $\mathrm{A}$ " was due to adsorption effects and hence could be removed by heating in vacuo or keeping the films under dynamical vacuum for a longer period.

The activation energy varied from 0.7 to $0.9 \mathrm{eV}$ for films of thicknes varying from $50000 \AA$ to $1000 \AA$. It was also noticed that as for lead sulphide $\Delta E$ increased with decrease of film thickness.

\section{Thermoelectric Power $\alpha$}

PbS films: Fig. 3 shows typical integral thermal e.m.f. vs. temperature difference curves for a film of thickness $33000 \AA$ (Curve 1). It is seen that the thermal e.m.f. increased gradually with rise of temperature difference, reaching a maximum, and then falling steeply to zero. With further increase of temperature difference the thermal e.m.f. changes its sign. During cooling a slightly different path $\left(\mathrm{l}^{\prime}\right)$ is followed though similar in nature to that of heating (path 1). The thermal e.m.f. was slightly smaller during cooling than during heating. Fig. 4 shows the coresponding thermoelectric power for different temperature regions. It can be seen that the thermo-

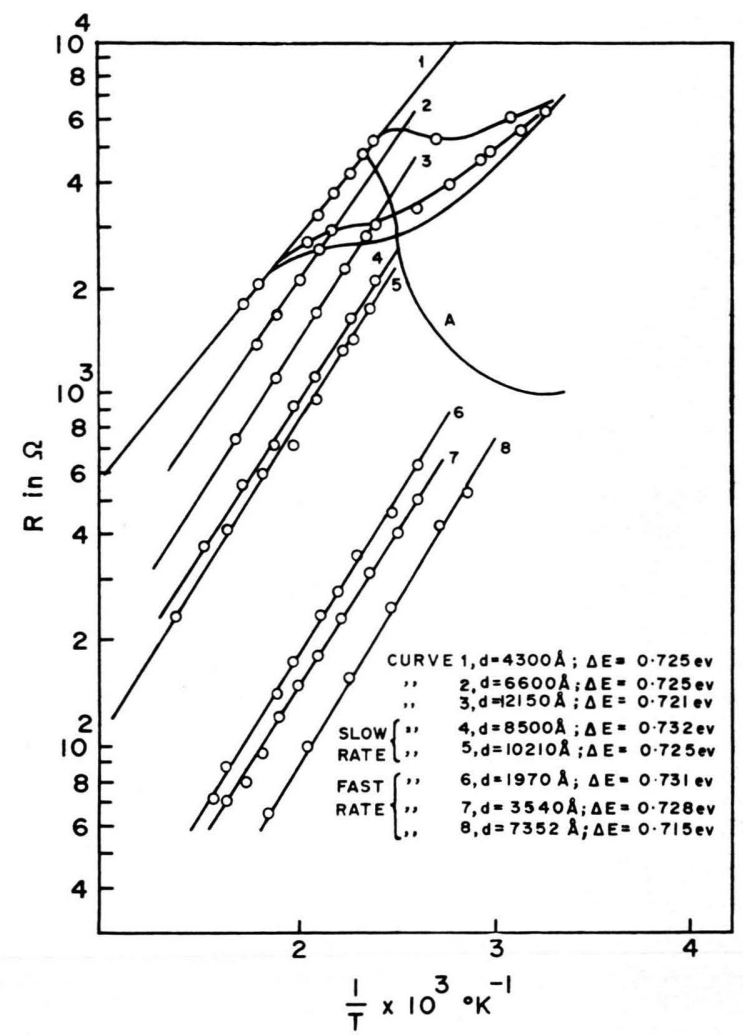

Fig. 2. Variation of $\log R$ with $1 / T$ for $\mathrm{PbSe}$ films of different thickness.

electric power changes sign when proceeding from the low temperature p-type to the high temperature n-type region. On cooling, the thermoelectric power changes its sign from negative to positive but the

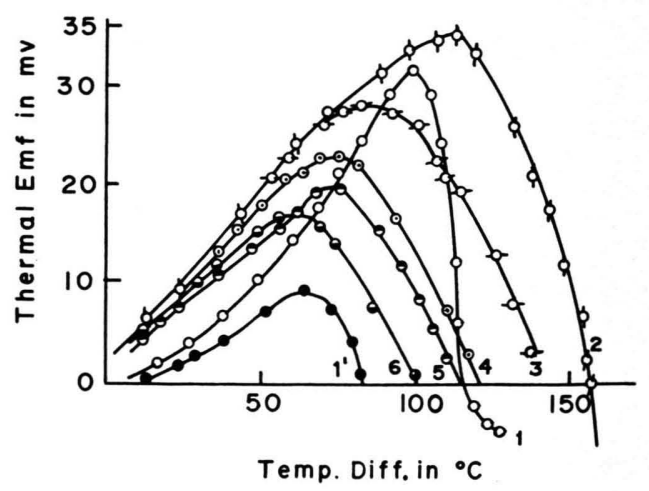

Fig. 3. Variation of thermal e.m.f. with temperature difference between two ends for $\mathrm{PbS}$ film

Curve 1 : obtained during heating

Curve $1^{\prime}$ : obtained during cooling

Curves 2-6: obtained for different temperatures of the cold end.

$\left(2: 30^{\circ} \mathrm{C}, 3: 60^{\circ} \mathrm{C}, 4: 80^{\circ} \mathrm{C}, 5: 100^{\circ} \mathrm{C}, 6: 120^{\circ} \mathrm{C}\right)$. 
inversion temperature did not necessarily coincide with that on heating.

It may be pointed out here that if the thermoelectric power was measured below the inversion temperature, the heating and cooling curves followed almost the same path. As can be seen from Fig. 5 the thermoelectric power increased with decrease of the film thickness. While studying the dependance of the thermal e.m.f. and the point of inversion on the cold junction temperature, it was noticed that with increase of cold junction temperature the maximum thermal e.m.f. and the inversion temperature shifted towards lower temperatures (Fig. 3).

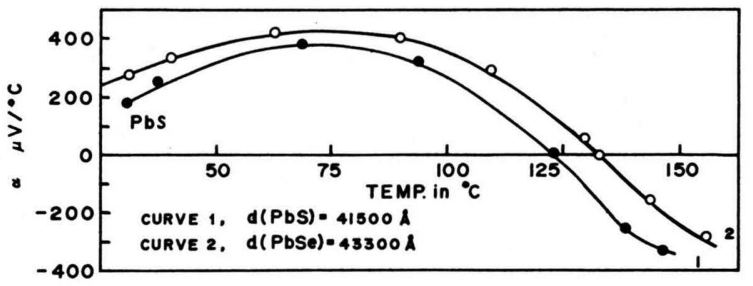

Fig. 4. Variation of thermoelectric power with temperature for $\mathrm{PbS}$ and $\mathrm{PbSe}$ films.

PbSe films: Curve 2 of Fig. 4 shows the variation of $\alpha$ with temperature. The general features of the curve are similar to those of $\mathrm{PbS}$ films. The variation of the thermoelectric power with film thickness at temperatures below the inversion point was similar to that of $\mathrm{PbS}$ (cf. Fig. 5).

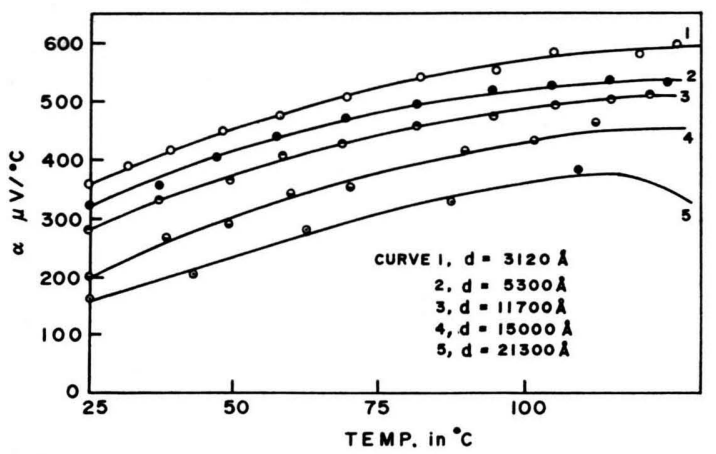

Fig. 5. Variation of thermoelectric power with temperature (below inversion temperature) for different thicknesses of $\mathrm{PbS}$ films.

\section{Temperature Coefficient of Resistance (TCR)}

The $T C R$ of these films defined as

$$
T C R=(\mathrm{l} / R) \cdot(\mathrm{d} R / \mathrm{d} T)
$$

was calculated both for PbS and PbSe films. Fig. 6 shows the variation of $T C R$ with temperature. The nature of the curves remained the same for other film thicknesses though the actual values differed to some extent. The maximum and minimum values of the TCR curves appeared to be dependent upon the rate of evaporation and the conditions of deposition.

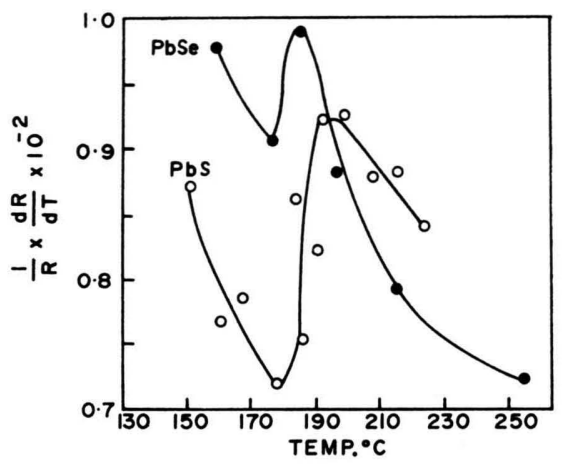

Fig. 6. Variation of $T C R$ with temperature for $\mathrm{PbS}$ and $\mathrm{PbSe}$ films.

\section{Hall Coefficient $R_{\mathrm{H}}$, Mobility $\mu_{\mathrm{H}}$ and Mean Free Path $l_{0}$}

The Hall coefficient of lead selenide films deposited at room temperature as well as at higher substrate temperature was measured in a manner described before ${ }^{19}$ and the HaLl mobility was calculated by using the relation $\mu_{\mathrm{H}}=\sigma R_{\mathrm{H}}$. Table 2

\begin{tabular}{|c|c|c|c|c|}
\hline \multirow{2}{*}{$T$} & Thickness & $\begin{array}{c}\sigma \\
1\end{array}$ & $\begin{array}{c}R_{\mathrm{H}} \\
\mathrm{cm}^{3}\end{array}$ & $\begin{array}{c}\mu_{\mathrm{H}} \\
\mathrm{cm}^{2}\end{array}$ \\
\cline { 2 - 4 } $27^{\circ} \mathrm{C}$ & $\AA$ & $\Omega \mathrm{cm}$ & Coulomb & Volt sec. \\
& 27700 & 15.11 & 0.502 & 7.573 \\
& 17800 & 14.80 & 0.496 & 7.345 \\
& 15360 & 13.50 & 0.480 & 6.987 \\
& 10020 & 11.70 & 0.300 & 4.550 \\
& 5040 & 9.174 & 0.149 & 3.263 \\
& 12200 & 15.20 & 0.952 & 14.460 \\
& 8510 & 13.35 & 0.892 & 11.980 \\
& 6730 & 11.35 & 0.866 & 9.830 \\
& 3910 & 10.10 & 0.554 & 5.350 \\
\hline
\end{tabular}

Table 2. $R_{\mathrm{H}}, \sigma$ and $\mu_{\mathrm{H}}$ of PbSe films (p Type) deposited at different substrate temperatures $T$.

shows $R_{\mathrm{H}}, \sigma$, and $\mu_{\mathrm{H}}$ for films of different thicknesses deposited more or less under the same conditions. It is clearly seen that the mobility decreased in each case with decrease of film thickness. However, the higher substrate temperature favoured higher mobility as seen from an increase both in 
Hall coefficient and conductivity. The latter effect was reported in previous papers ${ }^{20,21}$.

The mean free path of the charge carriers at different temperatures was obtatined graphically for PbSe films from $\varrho d$ vs. $d$ curves as was done previously for $\mathrm{PbTe}$ films ${ }^{20}$. The Fig. 7 shows $\varrho d$ vs. $d$

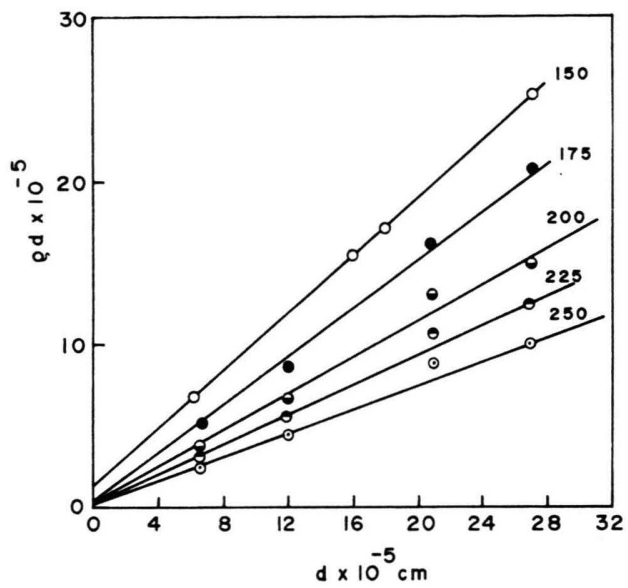

Fig. 7. Variation of $\varrho d$ with $d$ at different temperatures for PbSe films.

curves for different temperatures and Table 3 shows the variation of the mean free path with temperature. The mean free path decreases with increasing temperature. It is also posible to calculate the mo-

\begin{tabular}{|c|c|}
\hline$T$ & $\begin{array}{c}l_{0} \\
\mathrm{~cm}\end{array}$ \\
$0 \mathrm{C}$ & $3.86 \times 10^{-5}$ \\
\hline 150 & $1.42 \times 10^{-5}$ \\
175 & $1.19 \times 10^{-5}$ \\
225 & $0.74 \times 10^{-5}$ \\
\hline 250 & \\
\hline
\end{tabular}

Table 3. Variation of mean free path $l_{0}$ with temperature $T$.

bility from $l_{0}$ by using an expression based on the LoRENTZ-Sommerfeld theory,

$$
\mu=\frac{l_{0} e}{225 \sqrt{ } 2 \pi m^{*} k T} \frac{\mathrm{cm}^{2}}{\mathrm{Vs}}
$$

where the symbols have their usual meaning. Since $l_{0}$ is a function of temperature, hence $\mu \sim T^{-n}$ where $n$ is a characteristic of the material. The value of $n$ calculated from $\log \mu$ vs. $\log T$ plots was found to be approximately 4 for $\mathrm{PbSe}$ films.

21 V. D. Deokar and A. Goswami, Indian J. Pure Appl. Phys., in press.

22 E. H. Sondheimer, Advan. Phys. 1, 1 [1952].

\section{Discussion}

Previous studies of thin $\mathrm{PbTe}$ films revealed that some of the semiconducting parameters i. e. resistivity, activation energy, HaLL coefficient, mobility, $T C R$ and thermoelectric power etc. are considerably dependent on film thickness, substrate temperature and deposition conditions. The present study confirms these findings for $\mathrm{PbS}$ and $\mathrm{PbSe}$ films.

Sondheimer's theory ${ }^{22}$ qualitatively explains the increase of resistivity with the decrease of film thickness through the fact of lower mean free path, but it is inadequate when studied quantitatively. As already pointed out in our previous paper ${ }^{20}$ real films contain voids, discontinuities, defects and imperfections such as stacking faults, twin structures, intercrystalline boundaries etc. at least during the initial stage of their growth. At a later stage, however, these deposited layers may merge into a continuous film eventually developing surface asperities depending upon the evaporation conditions. Lucas ${ }^{23}$ has already pointed out that because of the presence of surface unevenness the resistivities of films are considerably higher than that of the corresponding bulk material.

The conductivity $\sigma$, in the case of metallic films, based on the island structure theory of NEUGEBAUER ${ }^{24}$ is given by the expression

$\sigma=A \frac{\sqrt{2 m \Phi}}{h^{2} d^{\prime}} \cdot \exp \left\{-\frac{4 \pi d^{\prime}}{h} \sqrt{2 m \Phi}\right\} \cdot B \exp \left\{-\frac{e^{2} / \varepsilon r}{k T}\right\}$

where $A$ and $B$ are constants. According to WiLson's theory $B$ depends upon the mean free path $l_{0}$.

$\Phi$ - the potential barrier between two islands,

$e$ - the electronic charge,

$m$ - the electronic mass,

$r$ - the average radius of an island,

$d^{\prime}$ - the distance between islands,

$k$ - Boltzmans's constant,

$h$ - Planck's constant,

$\varepsilon$ - dielectric constant.

The above formula may be modified in case of thin films of semiconductors by taking into account the energy required to excite an electron from the valence to the conduction band. Then

$$
\begin{aligned}
& \sigma=A^{\prime} \frac{\sqrt{2 m \Phi}}{h^{2} d^{\prime}} \\
& \cdot \exp \left\{-\frac{4 \pi d^{\prime}}{h} \sqrt{2 m \Phi}-\frac{2 e^{2} / \varepsilon r+\Delta E_{g}}{2 k T}\right\} .
\end{aligned}
$$

23 M. S. P. Lucas, J. Appl. Phys. 36, 5 [1961].

24 C. A. Nevgebauer, American Vacuum Soc., Trans. of 9th Vacuum Symp., California, New York 45 [1962]. 
From the above expressions, it is seen that the observed increase of $\Delta E$ with the decrease of film thickness can be explained in a better way through the exponential term of Eq. (3), because of the increase of $d^{\prime}$ and also the decrease of $r$ with decrease of film thickness. The explanation for the variation of the $T C R$ with temperature in the present case is similar to that pointed out for lead telluride films ${ }^{20}$.

The peculiar features of the thermoelectric power can be explained from the general expression of $\alpha$ given by

$$
\alpha_{\mathrm{n}, \mathrm{p}}=-\frac{k}{e} \frac{n \mu_{\mathrm{e}}\left[\left(\frac{5}{2}-s\right)+\ln \left(N_{0} / n\right)\right]-p \mu_{\mathrm{n}}\left[\left(\frac{5}{2}-s^{\prime}\right)+\ln \left(N_{\mathrm{o}} / p\right)\right]}{n \mu_{\mathrm{e}}+p \mu_{\mathrm{n}}}
$$

It is well known that for a p-type material the FERMI level will rise with increase of temperature, attaining a maximum value eventually leading to a maximum value of the thermoelectric power. The change of sign of $a$ from positive to negative at higher temperature suggested that the contribution to the thermoelectric power of the first term in Eq. (4) is stronger than that of the second one. The reverse is the case below $135-175^{\circ} \mathrm{C}$ depending upon the thickness of the film. Since no intentional impurities were introduced into the specimens, the change of sign of $\alpha$ appears to be due to an increase of electron mobility as compared with hole mobility, the electron and hole concentrations being nearly equal (i. e. in the intrinsic range) at higher temperatures. A similar behaviour was also observed by Avafa ${ }^{25}$ et al., in the case of bulk $\mathrm{PbS}$. It has already been shown that the electron mobility is greater than the hole mobility for chalcogenides of lead ${ }^{26}$.

25 A. A. Avafa, I. S. Shafie, and F. S. A. Sultan, Z. Angew. Math. Phys. 7, 256 [1956].

26 R. H. Sмrth, Semiconductors, Cambridge University Press, London 1961, p. 421.
In the mobility relation $\mu \sim T^{-n}$, the value of $n$ was found to vary from 2.5 to 3 as observed by many workers ${ }^{2-6}$ for bulk material. We, on the other hand, have observed higher value of $n(\cong 4)$ for PbSe films. This increase appears to be due to the presence of faults and defects invariably associated with films. Smirnov ${ }^{27}$ whilst studying $n$ for $\mathrm{PbSe}$ (bulk) also concluded that the high value of $n \cong 4$ obtained by him was due to imperfections present in the crystals.

The increase of $R_{\mathrm{H}}$ as well as of $\mu$ with an increase in the substrate temperature has already been pointed out by Deokar and Goswami ${ }^{21}$ to be due to the removal of some of the defects present in the deposits. It is not easy to see the cause for the low values of the HALL coefficients of thin films compared to bulk material. It is however likely that these may arise out of the concellation of effects of majority and minority carriers.

27 I. A. Smirnov, B. Ya. Moizhes, and E. D. Nensberg, Soviet Phys. - Solid State 2, 1793 [1961]. 